\title{
The XIV Materia Symposium 2016 will discuss the theme Materials and Energy
}

The XIV version of the Materia Symposium (http://www.simposiomateria.com.br) will take place at the Tomorrow's Museum (www.museudoamanha.org.br), in Rio de Janeiro, from November 27th to December 3rd, 2016. The Materia Symposium accepts articles in all areas of study of Materials; however, the event will prioritize the theme Materials and Energy. Conferences and articles will be presented on materials for energy, with emphasis on new materials, nanoscience and new methodologies for the production and storage of energy, including the renewable energies of current use, such as hydroelectric, solar and wind, but also tidal and hydrogen energies, highlighting the use of biomasses and biofuels.

The main event will receive, as usual, the Itinerant School of Materials directed to graduate students and researchers. In the present edition, hydrogen energy research networks seminars will be jointly held. In addition to that, the organization of the XIV Materia Symposium will hold jointly with the Curators of the Tomorrow's Museum a Round Table open to the general public, with the objective to discuss the effects in the society of the main themes approached at the Materia Symposium, as a way to popularize the scientific knowledge in the area.

The Materia Symposium 2016 and the Itinerant School of Materials will discus the general theme Materials and Energy, considering that energy will be the great challenge of the XXI Century and that energy security will depend essentially on high performance new materials to become viable, with prominence to nanotechnology. Among the great challenges of the XXI Century, importance may be given to energy efficiency, as a way to alleviate the ever-growing demand, to homogenization of the energy supply in all regions, as a way to guarantee the access to food and humanitarian care to eradicate extreme poverty and, additionally, to limit and to mitigate the environmental impact of the anthropogenic actions. Ultimately, the Materia Symposium 2016 will contribute for satisfying such challenges. Furthermore, the Materia Symposium will act as an enabling element that will promote better scientific-technologic capacity of professionals that work on materials to be used in the energy sector, with emphasis on the production and storage of energy. The event will also stimulate the scientific community to discuss achievements in the area of hydrogen energy, as preparation for a marked position during the XXII World Hydrogen Energy Conference, which will be held in Rio de Janeiro in 2018 (http://www.labh2.coppe.ufrj.br/WHEC.php).

The Materia Journal will publish a selection of the articles to be presented at the Materia Symposium 2016 and I count on your contribution.

Cordially,

Paulo Emílio V. de Miranda

Editor-in-Chief

Materia Journal

E-mail: pmiranda@labh2.coppe.ufrj.br 